\title{
Mesoporous ZnO/AlSBA-15 (7) Nanocomposite as An Efficient Catalyst for Synthesis of 3,4-dihydropyrimidin- 2(1H)-one via Biginelli Reaction and Their Biological Activity Study
}

\author{
Birendra Nath Mahato*, T. Krithiga
}

Department of Chemistry, Sathyabama Institute of Science \& Technology, Chennai-600119, India

Received: $11^{\text {th }}$ March 2019; Revised: 8th August 2019; Accepted: 8th August 2019; Available online: 30th September 2019; Published regularly: December 2019

\begin{abstract}
In this study, the mesoporous $\mathrm{ZnO} / \mathrm{AlSBA}-15(\mathrm{Si} / \mathrm{Al}=7$ ) nanocomposite catalyst was prepared by using a combination of direct and impregnation procedure. The catalyst was characterized by X-ray diffraction (XRD), scanning electron microscope coupled with energy-dispersive x-ray spectroscopy (SEM-EDS), $\mathrm{N}_{2}$ adsorption-desorption isotherm, Fourier transform infrared spectroscopy (FT-IR), and Temperature programmed reduction (TPR- $\mathrm{H}_{2}$ ). The XRD and $\mathrm{N}_{2}$ sorption results show the hexagonal mesoporous nature of catalyst with type IV adsorption isotherm. The surface area was calculated by the BET method and found to be $373 \mathrm{~m}^{2} / \mathrm{g}$. From the TPR- $\mathrm{H}_{2}$ study, the reducibility temperature of $\mathrm{ZnO}$ found to be $966 \mathrm{~K}$. Further, the Biginelli reaction is a promising multi-component reaction in organic synthetic chemistry as it approaches the green chemistry protocols and adducts are extensively used as drugs, intermediate and in medicine. Hence, the catalytic activity was tested in one pot Biginelii reaction for the synthesis of 3,4-dihydropyrimidin-2 $(1 \mathrm{H})$-one's derivative. The product yield was observed to be $96 \%$ at temperature $333 \mathrm{~K}$, at the short response time of $4 \mathrm{~h}$. The two adducts were examined by ${ }^{1} \mathrm{HNMR}$, ${ }^{13} \mathrm{CNMR}$, and FT-IR spectroscopy. Besides, the biological activity of adduct (A) $\mathrm{C}_{15} \mathrm{H}_{18} \mathrm{~N}_{2} \mathrm{O}_{5}$ was explored by gram-positive bacteria (Staphylococcus aureus) and gram-negative microorganisms (E. coli). The adduct (A) $\mathrm{C}_{15} \mathrm{H}_{18} \mathrm{~N}_{2} \mathrm{O}_{5}$ shows a clear inhibition zone of $24 \mathrm{~mm}$ against E. Coli whereas Azithromycin shows an inhibition zone of $28 \mathrm{~mm}$. Copyright (C) 2019 BCREC Group. All rights reserved
\end{abstract}

Keywords: ZnO/AlSBA-15; Biginelli Reaction; Dihydropyrimidinone (DHPM); Antibacterial activity.

How to Cite: Mahato, B.N., Krithiga, T. (2019). Mesoporous ZnO/AlSBA-15 (7) Nanocomposite as An Efficient Catalyst for Synthesis of 3,4-dihydropyrimidin-2(1H)-one via Biginelli Reaction and Their Biological Activity Study. Bulletin of Chemical Reaction Engineering \& Catalysis, 14(3): 634-645 (doi:10.9767/bcrec.14.3.4469.634-645)

Permalink/DOI: https://doi.org/10.9767/bcrec.14.3.4469.634-645

\section{Introduction}

The functionalized mesoporous silica has shown excellent catalytic properties owing to the high surface area, ordered hexagonal pore with tunable pore diameter, greater wall thick-

* Corresponding Author.

E-mail: birendran1@gmail.com (B.N. Mahato);

Telp: +917978068818, Fax: +91-44-24502433 ness and high hydrothermal, mechanical stability [1-4]. Functionalization of mesoporous material can be effectively accomplished by different inorganic-organic species and very supremacy for numerous applications such as catalysis, separation, adsorption, optical/electronic devices and drug delivery $[5,6]$. Heterogeneous catalysis plays a rudimental role in the chemical industry in comparing to homogeneous catalysis as it ap- 
proaches green chemistry. Apart from this, it additionally recompenses the constraint of a homogeneous catalyst such as corrosion, the complication in separation, recyclability, etc. In the recent decade, metal oxide nanoparticles (NP) supported by mesoporous silica have much attention in the research field owing to their high reactivity, selectivity and abbreviated the reaction time of various organic synthetic reaction [7]. The Biginelli reaction is a onepot three-component reaction, extensively used in the synthesis of drug development, pharmaceutical and biologically active compound [8]. In particular, great inquisitiveness has been devoted to synthesizing 3,4-dihydropyrimidin-2 $(1 \mathrm{H})$-ones (DHPM) as it displays numerous activity such as anti-cancer $[9,10]$, calcium channel blocker, antihypertensive, antibacterial, antitumor, anti-inflammatory, and HIV agent $[11,12]$.

The heterogeneous catalyst, such as: $\mathrm{Fe}_{3} \mathrm{O}_{4} @$ Mesopourous SBA-15, Al-MCM-41, $\mathrm{FeCl}_{3} @ \mathrm{Al}-\mathrm{MCM}-41$, AlKIT, Zirconia sulfuric acid, $\mathrm{H}_{3} \mathrm{PW}_{12} \mathrm{O}_{40}$ [7,13-15,23], so far reported for this transformation. Dubey et al. demonstrated AlSBA-15 catalyst for DHPM derivative with maximum a yield of $72-80 \%$ in $24 \mathrm{~h}$ [16]. Recently, Bhuyan et al. investigated ZnO@SBA-15 in DHPM derivative [18]. Principally, Biginelli reaction is an acid catalyzed reaction. The acidity of the SBA- 15 family catalyst depends upon the type of metal and the amount of metal incorporated in the SBA-15 material framework. Dubey et al. prepared AlSBA-15 by post grafting technique. Such catalyst has the weakness of $\mathrm{Al}$ leaching during the reaction. The direct synthesis incorporates aluminum in the material framework and hence formation of Brønsted acid sites. Each one $\mathrm{Al}$ atom makes one Brønsted site. AlSBA-15 synthesized by direct method possesses greater activity and surface acidity than prepared by post-synthesis method [4]. Moreover, it is accepted that metal is leached out easily from solid support during the course of a reaction. This problem can be solved by direct synthesis method, as in the case of direct synthesis the metal atom was incorporated in the SBA-15 framework. Further, the catalytic activity of the catalyst can be enhanced by doping suitable metal oxide. $\mathrm{ZnO}$ is highly efficient in catalytic activity and has the credential of various multi-component reactions, coupling organic transformation [17].

Furthermore, antibiotic, also known as antibacterial, is the medicine mostly used to treat disease caused by bacteria and played a crucial role in good human health. It not only decreases the mortality rate but also enhances the life expectancy of human life. Antibacterial mainly either slow down the growth of bacteria or killed the bacteria. They cover a wide range of powerful drug and first antibacterial penicillin was discovered in 1928 by Alexander Fleming. Since then a broad spectrum of the advanced antibacterial drug was invented and used extensively for controlling, treating a variety of infection. The demand for new, effective antibacterial has been growing enormously. During the period 2000 to 2010, there was a $36 \%$ rise in consumption of antibacterial worldwide (in 71 countries), out of which BRICS countries alone accounting for $3^{\text {rd }}$ of $4^{\text {th }}$ [19]. Despite the increase in consumption, millions of children die per year due to pneumonia and sepsis [40], indicating there are limited access and improper use of these drugs. Therefore, there is an urgent need of new and effective antibacterial.

However, there is no study of bi-metallic SBA-15 catalyst in the synthesis of DHPM derivative. With this view, in this current work, we synthesized mesoporous AlSBA-15 (7) by direct synthesis as reported in the literature [4] and $\mathrm{ZnO}$ nano-particle were embedded onto it via wet impregnation technique. The prime goal of this study is to investigate the catalytic activity of bimetallic mesoporous $\mathrm{ZnO}$ /AlSBA15 (7) nano-composite on Biginelli reaction and antibacterial study of adducts.

\section{Materials and Methods}

\subsection{Material}

The chemicals Pluronic $123\left(\mathrm{EO}_{20} \mathrm{PO}_{70} \mathrm{EO}_{20}\right.$, $\mathrm{M}_{\mathrm{n}} \sim 5800$ ) (P123) purity 99.9\%, Tetraethyl Orthosilicate (TEOS) purity 99.99\%, Aluminium Isopropoxide (AIP) purity 99.99\% were procured from Sigma Aldrich Limited, India. Zinc acetate dihydrate (purity 99\%), Concentrated $\mathrm{HCl}$ (37\%), Polyethylene Glycol (PEG-400), Urea purity $99 \%$ was purchased from Merck Limited, India. Ethyl Acetoacetate, Nitrobenzaldehyde, vanillin were purchased from Ranbaxy Limited, India. All chemicals were AR grade and used as supplied.

\subsection{Synthesis of AlSBA-15 (7)}

The mesoporous AlSBA-15 with $\mathrm{Si} / \mathrm{Al}$ ratio 7 was prepared by utilizing Pluronic (P123) as a template, TEOS and AIP as silica and aluminum source respectively. $4 \mathrm{~g}$ of $\mathrm{P} 123$ was dissolved in $10 \mathrm{~mL} 2 \mathrm{M} \mathrm{HCl}$, then $90 \mathrm{~mL}$ of Distilled water was added and stirred. Temperature maintained at $313 \mathrm{~K}$. To this arrangement, $9 \mathrm{~g}$ of TEOS and the required amount of AIP was added slowly with mixing. The reac- 
tion blend is treated hydrothermally in a polypropylene lined Stainless Steel Autoclave for 24 h. After hydrothermal treatment, the solid product is filtered off, dried at $373 \mathrm{~K}$ in a hot air oven. The resulting white product was calcined at $823 \mathrm{~K}$ for $12 \mathrm{~h}$. The sample was denoted as AlSBA-15 (7).

\subsection{Synthesis of $\mathrm{ZnO} / \mathrm{AlSBA}-15$ (7)}

The $\mathrm{ZnO}$ nanoparticles were impregnated on to AlSBA-15 (7) by wet incipient impregnation method. In a typical synthesis, $0.1 \mathrm{~g}$ of zinc acetate was dissolved in $50 \mathrm{~g}$ of Distilled water. To this mixture, $0.1 \mathrm{~g}$ of Polyethylene Glycol (PEG -400) was added and $\mathrm{pH} 9.0$ was obtained by addition of ammonia solution and kept at $348 \mathrm{~K}$ for overnight. Then the solution was cooled down to room temperature normally. To this solution, $1 \mathrm{~g}$ of AlSBA-15 (7) catalyst was added and sonicated for $30 \mathrm{~min}$. Consequently, the precipitate was filtered off, dried at $353 \mathrm{~K}$ and was calcined at $673 \mathrm{~K}$ for $10 \mathrm{~h}$. This is denoted as $\mathrm{ZnO} / \mathrm{AlSBA}-15$ (7) catalyst.

\subsection{Characterization of Catalyst}

The wide-angle powder X-ray diffraction pattern of ZnO/AlSBA-15 (7) catalyst was collected by Philips X'Pert Pro diffractometer in

Table 1. XRD diffraction results

\begin{tabular}{ccccc}
\hline Sample & $\begin{array}{c}I_{100^{\mathrm{a}}} \\
(\mathrm{a} . \mathrm{u})\end{array}$ & $\begin{array}{c}2 \theta \\
(100)\end{array}$ & $\begin{array}{c}d_{100^{\mathrm{b}}} \\
(\AA)\end{array}$ & $\begin{array}{c}\mathrm{a}^{\mathrm{c}} \\
(\AA)\end{array}$ \\
\hline ZnO/AlSBA-15(7) & 4489 & 0.94 & 93.9 & 108.42 \\
\hline
\end{tabular}

a Intensity of the reflection peak.

b (100) interplanar spacing, $n \lambda=2 d_{100} \sin \theta$.

c Unit cell determined for a hexagonal symmetry, $a_{0}=2 d_{100} / \sqrt{ } 3$

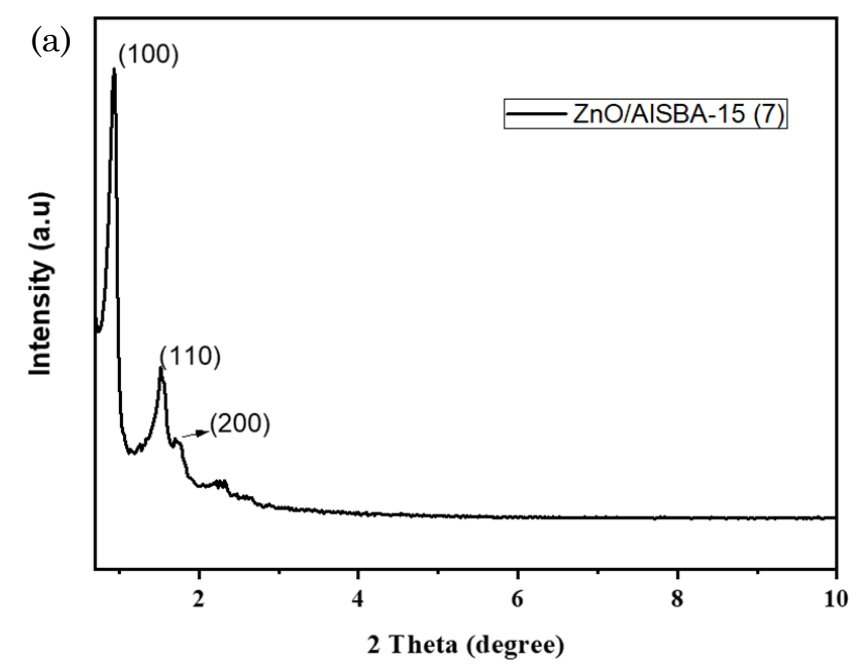

the $2 \theta$ range from $10^{\circ}-90^{\circ}$, using $\mathrm{Cu} \mathrm{K} \alpha$ source $(\lambda=1.54 \AA)$ at the scan step rate of 0.02 . The low angle powder X-ray diffraction pattern of ZnO/AlSBA-15 (7) was recorded by Advance D8 (Bruker) X-ray diffractometer in the $2 \theta$ range from 0.6 to $10^{\circ}$. The SEM image was recorded by FEI QUANTA 200 FEG High-Resolution SEM. Nitrogen adsorption isotherm was recorded in Nova e 2200, (Quantachrome) coupled with ASiQwin software. Before analysis, the sample was outgassed at $373 \mathrm{~K}$ for $2 \mathrm{~h}$. The surface area was determined by applying the Brunauer-Emmett-Teller (BET) equation. The pore size was calculated using the BarrettJoyner-Halenda (BJH) method by taking the desorption branch of the isotherm. The TPR- $\mathrm{H}_{2}$ was recorded in Micrometric Chemisorb 2750 with heating rate $10 \mathrm{~K} / \mathrm{min}$. FT-IR spectrum was performed on the Bruker Alpha-T from 400-4000 $\mathrm{cm}^{-1}$. The DHPM adducts were characterized by FT-IR (Bruker Alpha-T) and NMR (Bruker $400 \mathrm{MHz}$ ).

\subsection{Catalytic Studies}

A mixture of the aldehyde (1 mmol), ethyl acetoacetate $(1 \mathrm{mmol})$, urea $(1.4 \mathrm{mmol})$, ethanol (5 ml) and Zno@AlSBA-15 (7) catalyst was taken in a two neck round bottom flask. Stirred and reflux at $333 \mathrm{~K}$. The reaction is monitored by Thin Layer Chromatography. After completion, the catalyst was separated by filtration and the solvent was evaporated to obtain the solid product. It is then recrystallized from ethanol. The yield of product was calculated from re-crystallized weight, based on aldehyde. The product was characterized by ${ }^{1} \mathrm{H}$ NMR, ${ }^{13} \mathrm{C}$ NMR, and FT-IR.

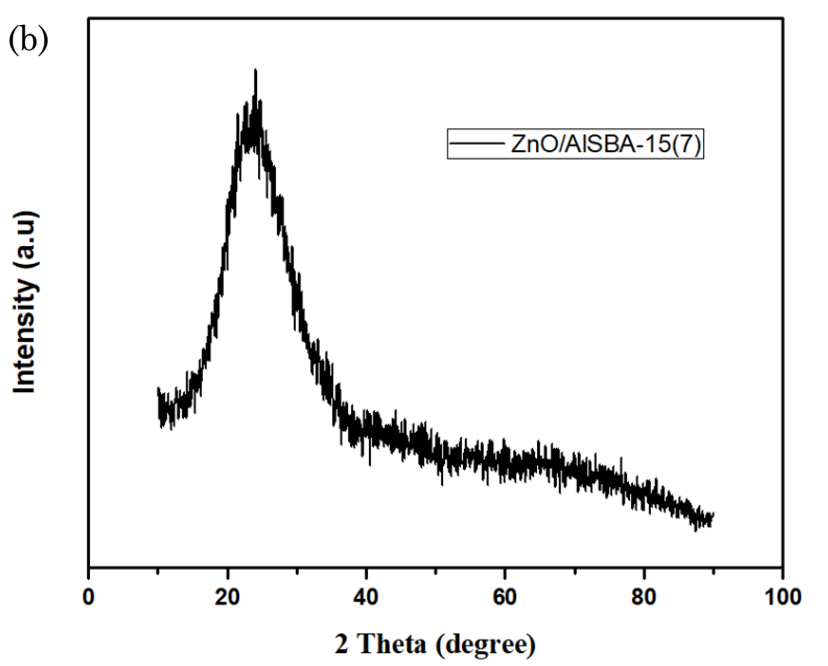

Figure 1. (a) Low angle XRD of ZnO/AlSBA-15(7), (b) Wide-angle XRD pattern. 
2.6 Antibacterial Investigation of DHPM Derivative

The gram-negative bacteria Escherichia coli and gram-positive bacteria Staphylococcus aureus pathogens were used to screen the antibacterial activity of product by using Agar well diffusion method [24]. The strain was collected from the Microbial Type Culture Collection (MTCC), Chandigarh, India.

In this method, $25 \mathrm{~mL}$ of Mueller Hinton agar was poured into a sterile Petri plate (Himedia, Mumbai, India). The plates were left for solidification, after which $18 \mathrm{~h}$ grown (OD adjusted to 0.6$) 100 \mu \mathrm{L}$ of pathogenic bacteria cultures were transferred onto a plate and made culture lawn by using sterile the cotton swab. The arrangement left for $5 \mathrm{~min}$ for setting and $5 \mathrm{~mm}$ well was made by employing a sterile cork borer. The test samples were dissolved in DMSO and loaded into wells with various concentrations such as $25 \mu \mathrm{g} / \mathrm{well}, 50$ $\mu \mathrm{g} / \mathrm{well}, \quad 75 \mu \mathrm{g} / \mathrm{well}$, and $100 \mu \mathrm{g} / \mathrm{well}$. The Azithromycin and solvent served as positive and negative control respectively. The plates were incubated at $310 \mathrm{~K}$ in a $40 \mathrm{~W}$ fluorescent light source ( $400 \mathrm{~nm})$ for $24 \mathrm{~h}$. The zone of inhibition around the well was measured by using an antibiotic zone scale (Himedia, Mumbai, India). The results are presented in Table 4 .

\section{Results and Discussion}

\subsection{Physiochemical Properties of the Catalyst}

The low angle XRD pattern of $\mathrm{ZnO} / \mathrm{AlSBA}$ 15 (7) catalyst shown in Figure 1(a). The three peaks indexed to the plane (100) (110) and (200) indicates long-range mesoporous with two-dimensional hexagonal symmetry (Space group P6mm) [3]. The length of unit cell was calculated by using formula $\mathrm{a}_{0}=2 d_{100} / \sqrt{ } 3$. The unit cell parameters are represented in Table 1. The wide-angle XRD pattern of $\mathrm{ZnO} / \mathrm{AlSBA}$ 15 (7) catalyst is shown in Figure 1(b). The broadband from $20^{\circ}$ to $30^{\circ}$ indicates the mesoporous AlSBA-15. The crystalline phase of nano $\mathrm{ZnO}$ is not prominent in the spectrum as the $\mathrm{Zn} \%$ in $\mathrm{ZnO}$ /AlSBA-15 (7) is only 2.03\% (confirmed from EDS data), which indicates the uniform dispersion of $\mathrm{ZnO}$ [21]. Jiang et al. showed that the crystalline phase of $\mathrm{ZnO}$ nor-
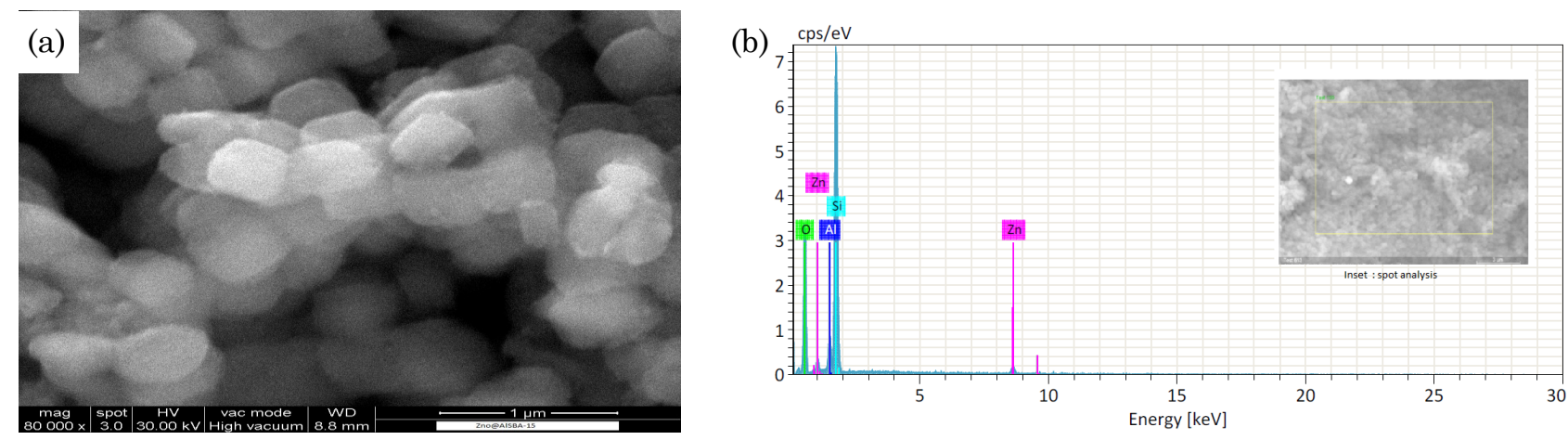

Figure 2. (a) SEM image of $\mathrm{ZnO} / \mathrm{AlSBA}-15$ (7), (b) EDS data of $\mathrm{ZnO} / \mathrm{AlSBA}-15$ (7) catalyst.

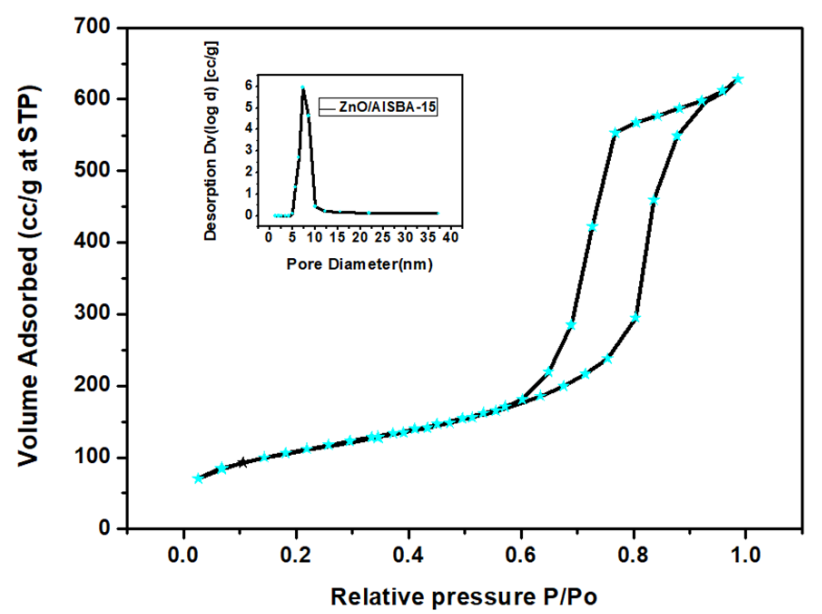

Figure 3. $\mathrm{N}_{2}$ Adsorption-desorption isotherm, inset graph (Pore size distribution).

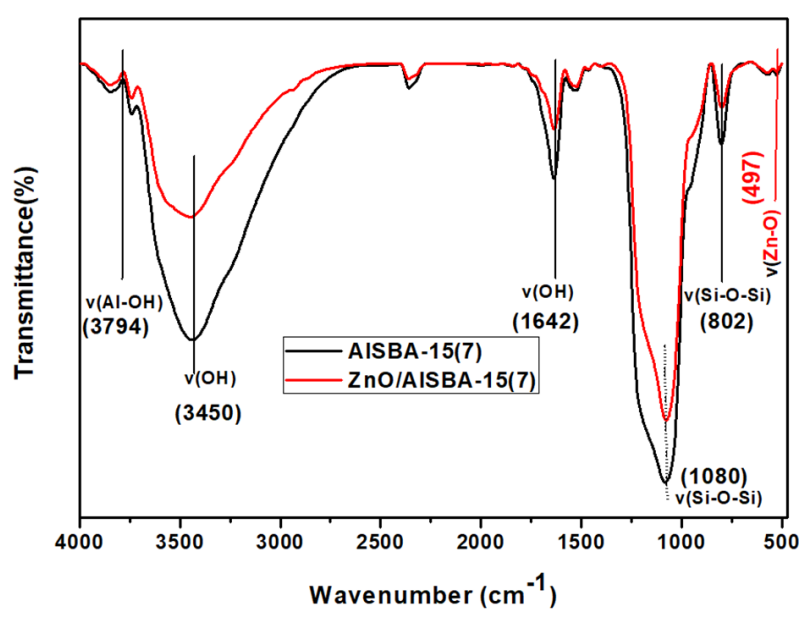

Figure 4. FT-IR Spectrum of AlSBA-15(7) and $\mathrm{ZnO} / \mathrm{AlSBA}-15(7)$. 
mally starts to appear at $50 \% \mathrm{ZnO}$ doped in aluminosilicate SBA-15 and there was an absence of a peak in case of $30 \% \mathrm{ZnO}$ doped in SBA-15 [21]. The crystallite size of $\mathrm{ZnO} / \mathrm{AlSBA}$ 15 (7) catalyst was calculated by using Scherrer equation $\mathrm{D}=0.9 \lambda / \beta \cos \theta$ where $\lambda$ is wavelength and $\beta$ is FWHM. The average Crystallite size is found to be $24 \mathrm{~nm}$.

Figure 2(a) represents the SEM images of ZnO/AlSBA-15 (7) catalyst; from the SEM images it is evident that the morphology of catalyst is hexagonal. From the EDS data, we found $2.03 \%$ of $\mathrm{Zn}$ is embedded in the pore of AlSBA15(7). Further, from EDS data (Figure 2(b)), the elemental composition of $\mathrm{ZnO} / \mathrm{AlSBA}-15(7)$ catalyst found to be Oxygen $64.13 \%$, Si $27.16 \%$, $\mathrm{Al} 6.68 \%$ and $\mathrm{Zn} 2.03 \%$ by mass. These data confirm the presence of $\mathrm{ZnO}$ in $\mathrm{ZnO}$ /AlSBA-15 (7) catalyst.

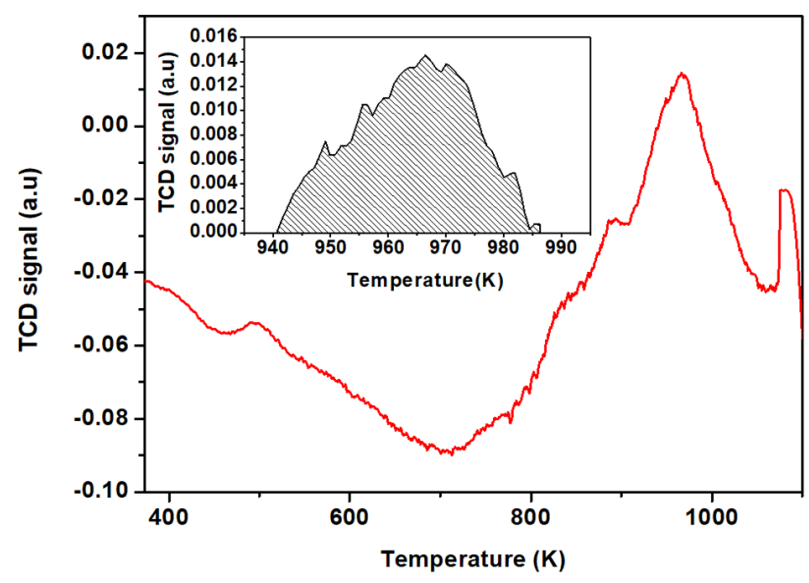

Figure 5. TPR- $\mathrm{H}_{2}$ of $\mathrm{ZnO} / \mathrm{AlSBA}-15$ (7) catalyst; (inset graph shows area analysis)
The surface properties of ZnO/AlSBA-15 (7) catalyst were determined by using $\mathrm{N}_{2}$ adsorption-desorption isotherm obtained from Nova e 2200 (Quantachrome). Figure 3 illustrates the $\mathrm{N}_{2}$ adsorption- desorption isotherm curve and inset graph shows pore size distribution. The surface area, pore volume and pore diameter calculated to be $373 \mathrm{~m}^{2} / \mathrm{g}, 1.019 \mathrm{cc} / \mathrm{g}$, and 7.31 $\mathrm{nm}$, respectively. It is clear that the catalyst showing type IV isotherm along with $\mathrm{H} 1$ hysteresis loops and pore distribution curves, which confirms the monodispersed order mesoporosity [20,21]. The FT-IR spectra of AlSBA-15 (7) and $\mathrm{ZnO} / \mathrm{AlSBA}-15$ (7) are presented in Figure 4. The broad absorption band in range 3700$3300 \mathrm{~cm}^{-1}$ is due to hydrogen bond and $\mathrm{Si}-\mathrm{O}-\mathrm{H}$ bond. The weak absorption around $3700 \mathrm{~cm}^{-1}$ attributed to $\mathrm{Al}-\mathrm{OH}$ species, which is because of the $\mathrm{OH}$ stretching vibration of $\mathrm{Si}-\mathrm{OH}-\mathrm{Al}$ groups in mesoporous aluminosilicate [22]. The peak at $1642 \mathrm{~cm}^{-1}$ is due to $\mathrm{O}-\mathrm{H}$ bending mode which diminished in $\mathrm{ZnO} / \mathrm{AlSBA}-15$ (7) catalyst as compare to AlSBA-15 (7), which is the consequence of condensation of the silanol group. The observed peak around $1080 \mathrm{~cm}^{-1}$ and 802 $\mathrm{cm}^{-1}, 580 \mathrm{~cm}^{-1}$ are attributed to asymmetric stretching and symmetric stretching of $\mathrm{Si}-\mathrm{O}-\mathrm{Si}$ groups respectively. The peak due to $\mathrm{Zn}-\mathrm{O}$ stretching vibration merges at $497 \mathrm{~cm}^{-1}$ of Si-O$\mathrm{Si}$ bands [18]. Besides these, we observe all peaks corresponds to AlSBA-15 also presents in $\mathrm{ZnO} / \mathrm{AlSBA}-15$ (7) catalyst.

The TPR- $\mathrm{H}_{2}$ was conducted for $\mathrm{ZnO} / \mathrm{AlSBA}$ 15(7) catalyst for understanding the reducibility properties of the catalyst. For this, $0.2497 \mathrm{~g}$ of sample was pretreated at $423 \mathrm{~K}$ in high pure helium gas (flow rate $25 \mathrm{cc} / \mathrm{min}$ ) for $1 \mathrm{~h}$. Then it

Table 2. Illustration of yield and time of two aldehydes

Entry

a yield calculated after re-crystallization based on aldehyde. 
was cooled to room temp in helium. Gas changed to $5 \% \mathrm{H}_{2} / \mathrm{Ar}(25 \mathrm{cc} / \mathrm{min})$ at room temp and waited till the baseline is stable. The TPR$\mathrm{H}_{2}$ was recorded from $298 \mathrm{~K}$ to $1123 \mathrm{~K}$ with heating rate $10 \mathrm{~K} / \mathrm{min}$. As can be seen in Figure 5 (TPR- $\mathrm{H}_{2}$ of catalyst), the only one reduction peak was observed at $966 \mathrm{~K}$, indicates the reduction temperature of $\mathrm{ZnO}$ to $\mathrm{Zn}$, which is supported by previously published literature $[38,39]$. This result suggests the homogeneous dispersion of $\mathrm{ZnO}$ in the catalyst. However, the reduction peak intensity was found to be low, suggesting the low $\mathrm{ZnO}$ content in the catalyst. The area under the curve gives the hydrogen consumption and was calculated to be $0.0527 \mathrm{~m}$ mole $\mathrm{H}_{2} / g$ catalyst. The low $\mathrm{ZnO}$ content in the catalyst was also discussed earlier in the SEMEDS section.

\subsection{Catalytic Studies}

To understand the catalytic activity of ZnO/AlSBA-15 (7) catalyst, the Biginelli condensation reaction was conducted by taking $p$ nitrobenzaldehyde, ethyl acetoacetate, and urea, as a model reaction, as shown in Figure 6. Ethanol $(5 \mathrm{ml})$ was used as a solvent for all the reaction. The progress of the reaction was monitored by thin layer chromatography (TLC). However, for the synthesis of derivative, vanillin was used instead of $p$-nitrobenzaldehyde. Reaction condition was aldehyde (1 mmol), ethyl acetoacetate $(1 \mathrm{mmol})$, and urea (1.4 mmol) and $20 \mathrm{mg}$ catalyst ZnO/AlSBA-15 (7) catalyst. Finally, the data was compiled and tabulated in tabular form.

From the Table 3, it is evident that the product yield is high by using $\mathrm{ZnO} / \mathrm{AlSBA}-17$ (7) catalyst in compare to other functionalized mesoporous AlSBA-15. According to previously published literature $[28,30,34,23,16,7]$ on functionalized mesoporous silica, the yield of various substituted DHPM adducts is in between $62-92 \%$ with the experimental temperature range from $333 \mathrm{~K}$ to $363 \mathrm{~K}$, time 6-8 $\mathrm{h}$. On the other hand, in this present study, the $\mathrm{ZnO} /$ AlSBA-15 (7) catalyst produces a yield of $96 \%$ at temperature $323 \mathrm{~K}$ and reaction time 3-4 $\mathrm{h}$. This suggests that $\mathrm{ZnO}$ enhances the catalytic

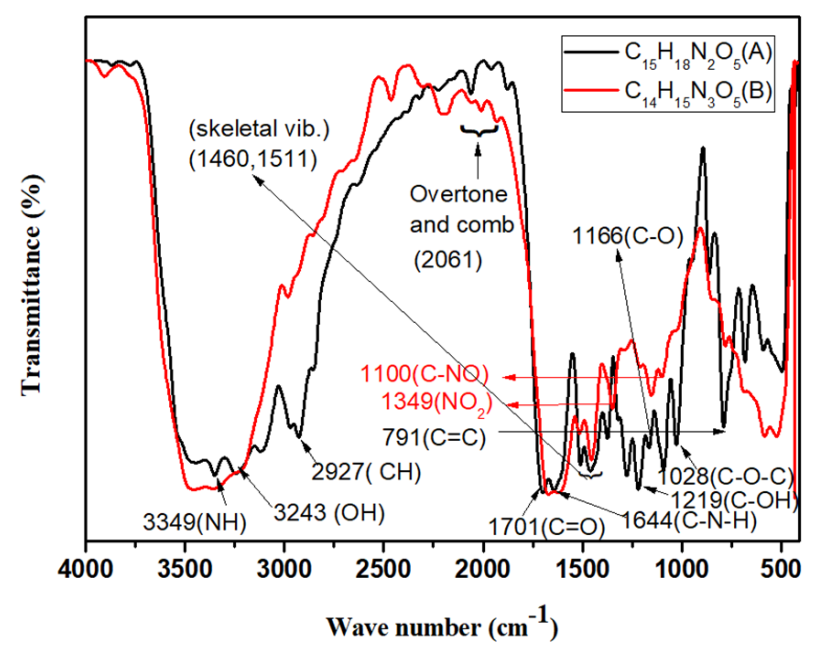

Figure 7. FTIR spectra of adduct (A) and (B).<smiles>[R]c1ccc(C=O)cc1[I-][I-]</smiles>
Ethyl acetoacetate<smiles>[R]c1ccc(C2NC(=O)NC(C)=C2C(=O)OCC)cc1</smiles>

Figure 6. Biginelli reaction

Table 3. Comparison of mesoporous catalysts employed for Biginelli reaction.

\begin{tabular}{cllccl}
\hline Sr. No. & $\begin{array}{c}\text { Aldehyde used for } \\
\text { the reaction }\end{array}$ & \multicolumn{1}{c}{ Catalyst } & Yield (\%) & Time (h) & Reference \\
\hline 1 & Nitrobenzaldehyde & Fe3O4 @SBA-15 & 84 & 5 & Reference-[7] \\
2 & -do- & AlSBA-15 & 89 & - & Reference-[16] \\
3 & -do- & ZnO@SBA-15 & 78 & 3.5 & Reference-[23] \\
4 & -do- & ZnO@AlSBA-15 & 95 & 3.2 & Present work \\
5 & Vanillin & ZnO@AlSBA-15 & 96 & 4 & Present work \\
\hline
\end{tabular}


reaction, which is in agreement with the literature $[28,16]$. Form the above discussion and finding, it can be concluded that our present catalyst shows fairly better catalytic activity with a shorter reaction time than reported mesoporous catalyst. Also, this study was conducted at a lower temperature with minimum use of solvent than the previously reported study. Therefore, it can be concluded that the reaction was performed in the milder reaction condition. Furthermore, the DHPM was confirmed by NMR and FTIR spectra, of which spectral data presented herein.

\subsection{Structure Elucidation of Adducts}

The two DHPM adducts (A) and (B) are characterized by FTIR and NMR. The adduct (A) is a solid, orange in color and empirical formula is $\mathrm{C}_{15} \mathrm{H}_{18} \mathrm{~N}_{2} \mathrm{O}_{5}$. The empirical formula of adduct (B) is $\mathrm{C}_{14} \mathrm{H}_{15} \mathrm{~N}_{3} \mathrm{O}_{5}$. It was a solid and creamy white in color.

The FTIR technique was used to get information about the functional group present in the adduct. The spectra of both the adduct (A) and (B) are presented in Figure 7. In the case of adducts (A), a strong absorption peak at $1701 \mathrm{~cm}^{-1}$ was observed, indicating the presence of a carbonyl group (carboxylic) in the adduct. The peak at 2927, 3243, and $3349 \mathrm{~cm}^{-1}$ corresponds to stretching of C-H, O-H, and N-H functional group respectively. Further, the peak at $1219 \mathrm{~cm}^{-1}$ and $1028 \mathrm{~cm}^{-1}$ corresponds to symmetric stretching of aromatic C-O-H and CO-C group respectively. The peak at 1460 and $1511 \mathrm{~cm}^{-1}$ indexed to aromatic C-H vibration. However, for the adduct (B), the peak at 1349 $\mathrm{cm}^{-1}$ corresponds to the symmetric stretching of aromatic C- $\mathrm{NO}_{2}$ group. The peak at 1515,1349 , and $792 \mathrm{~cm}^{-1}$ represents an aromatic nitro compound attached to an aromatic ring. The other prominent peak observed at $3454,2982,1672$, 1445 , and $1100 \mathrm{~cm}^{-1}$, which corresponds to O$\mathrm{H}$, - C- $\mathrm{H}, \mathrm{C}=\mathrm{O}$, aromatic ring $-\mathrm{C}-\mathrm{H}$, and $\mathrm{C}-\mathrm{N}$ functional group respectively. From these data, it can be concluded that adduct contains heteroatom with aromatic structure. Furthermore, the overtone and comb are present in the spectra around $2061 \mathrm{~cm}^{-1}$ and peak at 1460, 1511 $\mathrm{cm}^{-1}$ corresponds to pyridine skeletal vibration.

The ${ }^{1}$ HNMR of adduct (A) is displayed in Figure 8 . The chemical shift at 1.1 is a combination of a triplet $(3 \mathrm{H})$ and quartet $(2 \mathrm{H})$ indicates the presence of the ethyl group. A signal at $\delta(2.22)$ is assigned to the methyl group which shows a lower filed shifting for base signal (0.9) due to the presence of $\alpha-C=C$ bond. Hence this methyl group bonded to an aromatic ring. Similarly, singlet chemical shift at 3.7 is for methyl group and $\delta$ at 4.75 indicate the presence of ethylene group $\left(-\mathrm{O}-\mathrm{CH}_{2}\right)$. The two signals at $\delta(6.52,6.53)$ indicate the presence of

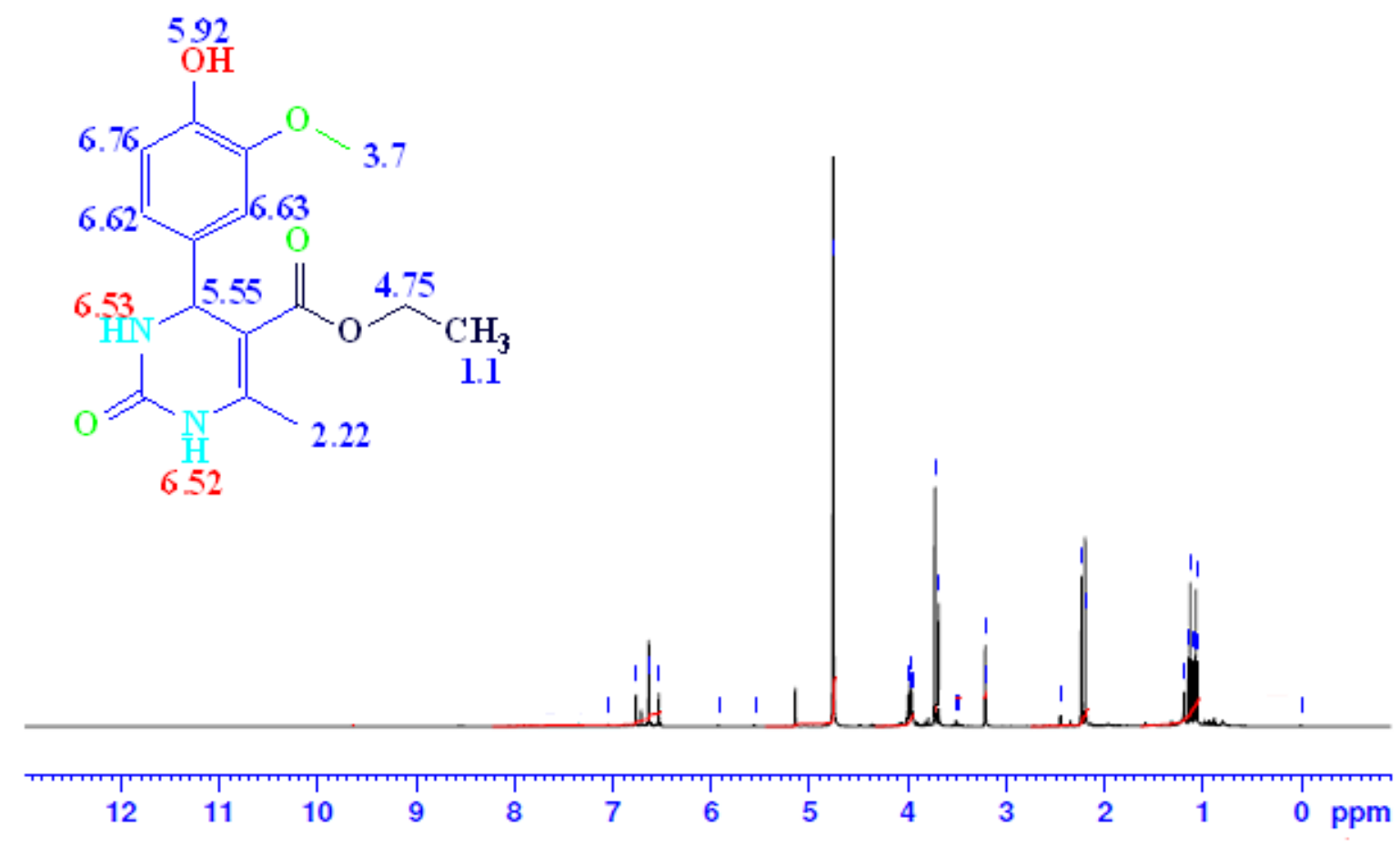

Figure 8. ${ }^{1} \mathrm{H}$ NMR spectrum of adduct (A) $\mathrm{C}_{15} \mathrm{H}_{18} \mathrm{~N}_{2} \mathrm{O}_{5}$ 


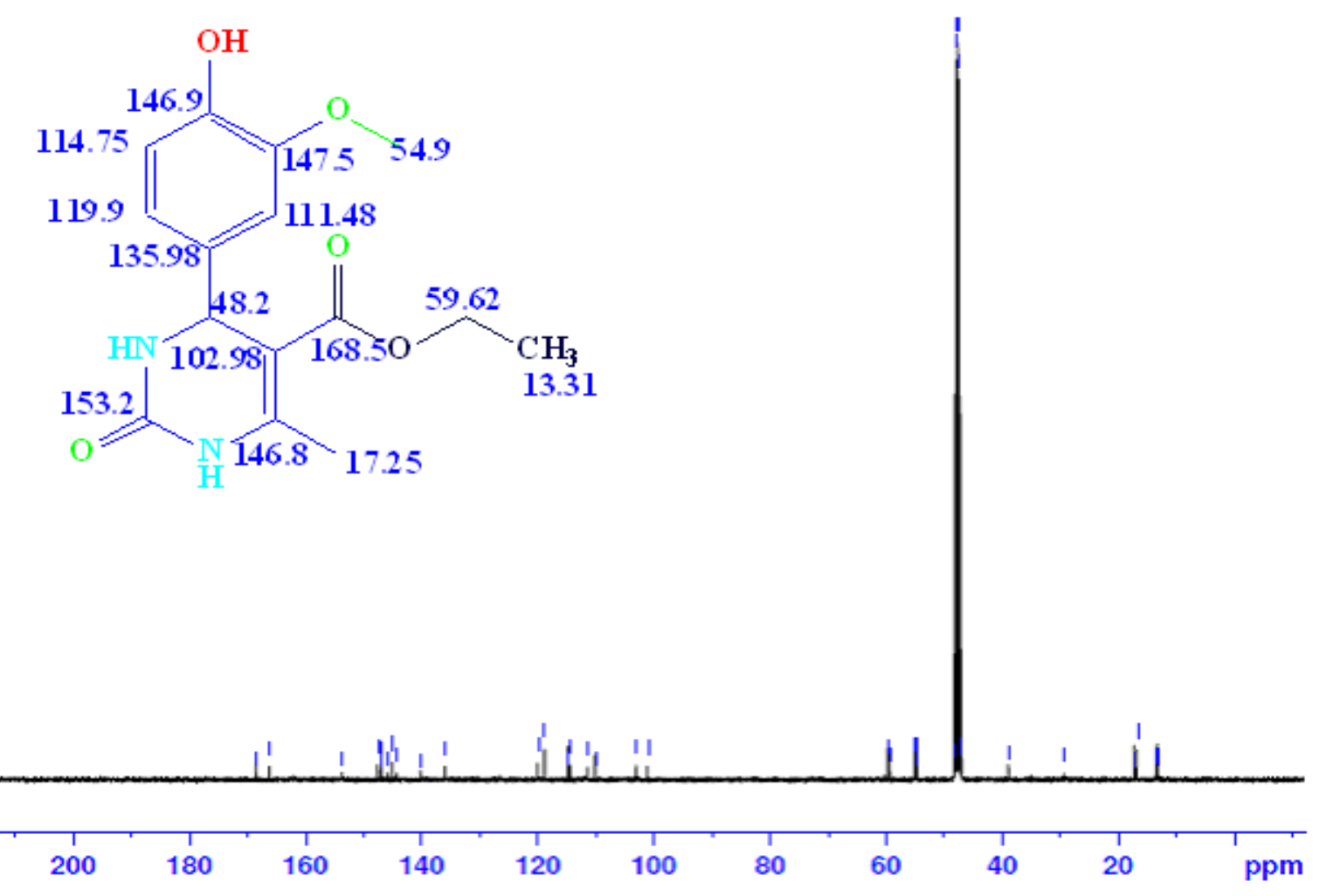

Figure 9. ${ }^{13} \mathrm{C}$ NMR of adduct (A) $\mathrm{C}_{15} \mathrm{H}_{18} \mathrm{~N}_{2} \mathrm{O}_{5}$
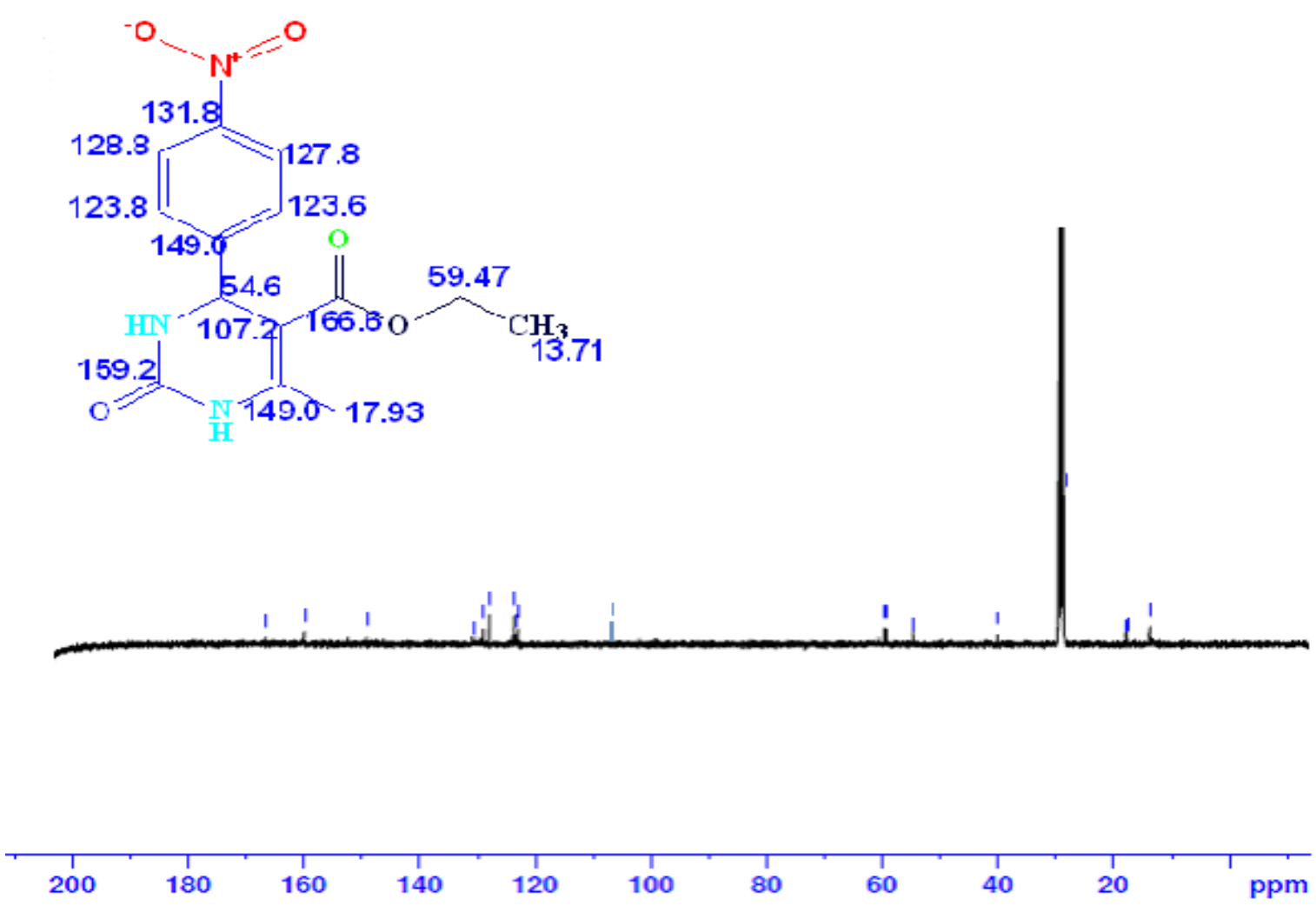

Figure 10. ${ }^{13} \mathrm{C}$ NMR of adduct (B) $\mathrm{C}_{14} \mathrm{H}_{15} \mathrm{~N}_{3} \mathrm{O}_{5}$ 
two $\mathrm{NH}$ of urea in an aromatic ring at para and ortho position. The signal observed at 6.62 , $6.63,6.73 \mathrm{ppm}$ is due to $\mathrm{CH}$ of the aromatic ring. The single signal at $\delta$ (5.92) indicates the presence of aromatic $\mathrm{O}-\mathrm{H}$ in the compound. Further, from the ${ }^{13} \mathrm{CNMR}$ spectrum, the signal at $168 \mathrm{ppm}$ indicates the presence of carboxylic (-C=O-O-R) carbon. The four signal at 111.4 , $119.9,114.7$, and $147.5 \mathrm{ppm}$ for aromatic carbon. A signal at 153.0 for the $(\mathrm{C}=\mathrm{O})$ group of an aromatic ring. In contrast, for adduct (B); the four signals at 123.8, 123.6, 127.8, $128.8 \mathrm{ppm}$ are for aromatic carbon. The signal at 131.8 ppm for aromatic C-NO $\mathrm{NO}_{2}$ carbon. $159.2 \mathrm{ppm}$ for the $\mathrm{C}=\mathrm{O}$ group of an aromatic ring. The structure of adducts along with their corresponding chemical shift value are presented as inset figure.

\subsection{Antibacterial Study}

Table 4 illustrates the antibacterial activity of DHPM $\left(\mathrm{C}_{15} \mathrm{H}_{18} \mathrm{~N}_{2} \mathrm{O}_{5}\right)$ in terms of Zone of Inhibition against the standard referrence Azithromycin. From the screening results we found that, the adduct (A) $\mathrm{C}_{15} \mathrm{H}_{18} \mathrm{~N}_{2} \mathrm{O}_{5}$ possesses excellent activity in gram-negative bacteria $E$. Coli and moderate active against gram-positive pathogen Staphylococcus aureus. Ghasemi et

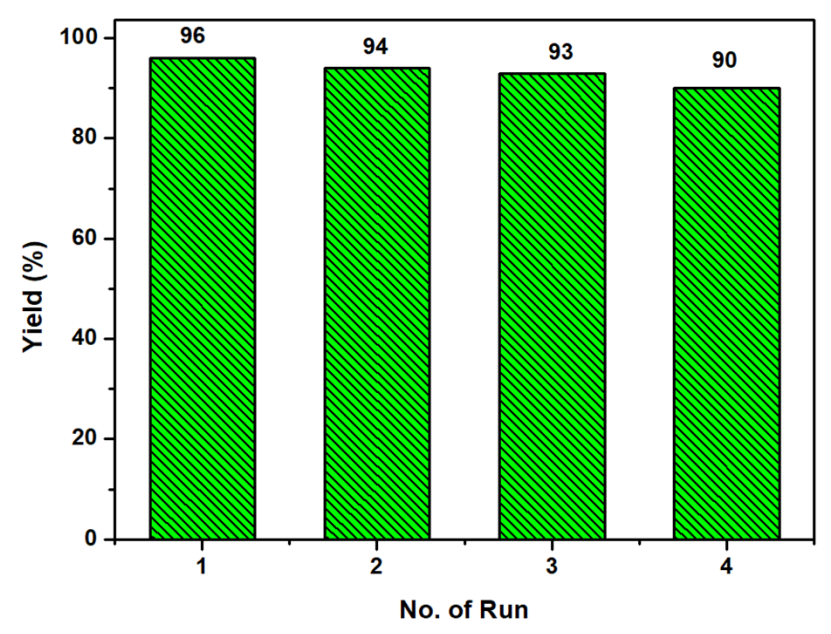

Figure 11. Recyclability of $\mathrm{ZnO} / \mathrm{AlSBA}-15$ (7) catalyst al. [28] investigated the antibacterial activity of DHPM derivative prepared by using mesoporous MCM- 41 catalyst. According to their finding, the maximum ZOI (mm) for E. Coli was 12 $\mathrm{mm}$ and for $S$. aureus was $14.4 \mathrm{~mm}$.

\subsection{Recyclability of Catalyst}

Reusability of heterogeneous catalyst is a significant parameter, which indicates the suitability of the catalyst. With this note, we studied the possibility of repeated use of ZnO/AlSBA-15 catalyst. For this, we recovered the catalyst by filtration, washed with ethanol, dried at $373 \mathrm{~K}$ in a hot air oven and were used up in another batch reaction. We continued the same process for consecutive four runs by applying the corrected weight of reactant according to loss of catalyst in each filtration. The results are depicted in Figure 11. It is evident that the catalyst possesses the capacity to produce $90 \%$ yield after four runs. In the very first run, catalyst produces a $96 \%$ yield of product and after $4^{\text {th }}$ run yield percentage was found to be $90 \%$. There is a minor observable loss of activity of catalyst after each run, which might be due to the block of active sites of the catalyst. Furthermore, the washed solution was analyzed by AAS and no zinc was detected. It indicates the non-leach ability of catalyst.

\section{Conclusion}

In summary, $\mathrm{ZnO} \mathrm{NP}$ modified mesoporous AlSBA-15 was synthesized with $\mathrm{Si} / \mathrm{Al}$ ratio of 7 . The average crystallite size of the catalyst is 24 $\mathrm{nm}$. The calculated textural properties of the catalyst such as surface area are $373 \mathrm{~m}^{2} / \mathrm{g}$, pore volume $1.019 \mathrm{cc} / \mathrm{g}$, and pore diameter $7.31 \mathrm{~nm}$. The reduction temperature of the $\mathrm{ZnO}$ to metallic $\mathrm{Zn}$ at the surface of the catalyst was evaluated to be $966 \mathrm{~K}$. The catalytic performance of the catalyst was performed on Biginelli Reaction. The $\mathrm{ZnO}$ promotes the catalytic property in conjunction with AlSBA-15, has a significant impact on the one-pot synthesis of 3,4 dihydropyrimidi-2 $(1 \mathrm{H})$-ones, resulting in milder condition of reaction such as less solvent use $(5 \mathrm{~mL})$, low temperature $(323 \mathrm{~K})$ and shorter reaction

Table 4. Antibacterial study of the adduct (A) $\mathrm{C}_{15} \mathrm{H}_{18} \mathrm{~N}_{2} \mathrm{O}_{5}$

\begin{tabular}{|c|c|c|c|c|c|}
\hline \multirow{2}{*}{$\begin{array}{l}\text { Name of Organism } \\
\text { Concentration }\end{array}$} & \multicolumn{3}{|c|}{$\begin{array}{c}\text { ZOI }(\mathrm{mm}) \\
\text { Sample }\end{array}$} & \multicolumn{2}{|c|}{$\begin{array}{c}\text { ZOI } \\
\text { Azithromycin } \\
\end{array}$} \\
\hline & $25 \mu \mathrm{g} / \mathrm{well}$ & $50 \mu \mathrm{g} / \mathrm{well}$ & $75 \mu \mathrm{g} / \mathrm{well}$ & $100 \mu \mathrm{g} / \mathrm{well}$ & $30 \mu \mathrm{g} / \mathrm{well}$ \\
\hline Staphylococcus aureus & 7 & 9 & 11 & 13 & 20 \\
\hline Escherichia coli & 20 & 21 & 22 & 24 & 28 \\
\hline
\end{tabular}


time $(4 \mathrm{~h})$ gives the best yield (96\%). Moreover, the $\mathrm{Al}$ metal leaching is very minor during the reaction; as it was prepared by the direct method and hence consequently maintains the acidity of the catalyst. Furthermore, the antibacterial activity of vanillin substituted DHPM adduct (A) $\mathrm{C}_{15} \mathrm{H}_{18} \mathrm{~N}_{2} \mathrm{O}_{5}$ shows inhibition zone of $24 \mathrm{~mm}$ for gram negative bacteria $E$. coli whereas standard Azithromycin shows $28 \mathrm{~mm}$. Further, the adduct (A) $\mathrm{C}_{15} \mathrm{H}_{18} \mathrm{~N}_{2} \mathrm{O}_{5}$ shows good antibacterial activity towards gram negative bacteria (E. coli) in compare to gram positive bacteria ( $S$. aureus). These finding suggests that the catalyst is effective in Biginelli reaction. The remarkable advantage of this method is easy work-up, excellent catalytic activity, short reaction time, better yield, recyclable and mild reaction condition.

\section{Acknowledgment}

We make great acknowledgment for timely analysis done by SAIF, IIT Madras, and Department of chemistry, IIT Madras, Chennai and Nanotechnology Research Centre, SRM University, Chennai. The author thanks to the management of Sathyabama Institute of Science and Technology, Chennai for their support to carry out this work.

\section{Reference}

[1] Cassiers, K., Linssen, T., Mathieu, M., Benjelloun, M., Schrijnemakers, K., Van Der, V.P., Cool, P., Vansant, E.F. (2002). A detailed study of thermal, hydrothermal, and mechanical stabilitiesof a wide range of surfactant assembled mesoporous silicas, Chem. Mater., 14: 2317-2324.

[2] Smith, K., Horwood, E. (1992). Solid Support and catalysts in organic Synthesis, PTR Prentice Hall, New York.

[3] Vinu, A., Murugesan, V., Böhlmann, W., Hartmann, M. (2004). An optimized procedure for synthesis of AlSBA-15 with large pore diameter and high aluminum content, $J$. Phys. Chem. B, 108(31): 11496-11505.

[4] Geden, A., Lassoued, A., Bonardet, J.L., Fraissard, J. (2001). Surface Acidity Diagnosis and Catalytic Activity of AlSBA-15 Materials Obtained by Direct Synthesis, Microporous and Mesoporous materials 44-45: 801-806.

[5] Wight, A.P., Davis, M.E. (2002). Design and Preparation of Organic-Inorganic Hybrid Catalysts, Chem. Rev., 102: 3589-3614.

[6] He, S., Han, C., Hang, H., Zhu, W., He, S., He, D., Luo, Y., (2015). Uptake of Arsenic (V) us- ing Alumina functionalized Highly Ordered Mesoporous SBA-15 (Al $\mathrm{Al}_{\mathrm{x}}$-SBA-15) as an effective Adsorbent. Journal of Chemical and Engineering Data, 60(5): 1300-1310.

[7] Mondal, J., Sen, T., Bhaumik, A. (2012). $\mathrm{Fe}_{3} \mathrm{O}_{4} @$ mesoporous SBA-15: a robust and magnetically recoverable catalyst for one-pot synthesis of 3,4-dihydropyrimidin-2(1H)-ones via the Biginelli Reaction. Dalton Transaction, 41: 6173-6181.

[8] Biginelli, P., Gazz, P. (1983). Synthesis of 3,4Dihydropyrimidin-2(1H)-Ones. Chim. Ital. 23: 360-416.

[9] Meyer, T.U., Kapoor, T.M., Haggarty, S.J., Mitchison, T.J. (1999). Small Molecule Inhibitor of Miotic Spindle Bipolarity Identified in a Phenotype-Based Screen. Science, 286(5441): 971-974.

[10] Haggarty, S.J., Mayer, T.U., Miyamoto, D.T., Fathi, R., King, R.W., Mitchison, T.J., Schreiber, S.L. (2000). Dissecting cellular processes using small molecules: identification of colchicine-like, taxol-like and other small molecules that perturb mitosis. Chemistry \& Biology, 7: 275-286.

[11] Kappe, O.C., (2000). Biologically active dihydropyrimidones of the Biginelli-type-a literature review, Eur. J. Med. Chem. 35: 10431052.

[12] Kappe, O. C., Shishkin, O.V., Uraya, G., Verdino, P. (2000). X-Ray Structure, Conformational Analysis, Enantioseparation, and Determination of Absolute Configuration of the Mitotic Kinesin Eg5 Inhibitor Monastrol. Tetrahedron, 56: 1859-1862.

[13] Shobha, D., Chari, M.A., Mano, A., Selvan, S.T., Mukkanti, K., Vinu, A. (2009). Synthesis of 3,4-dihydropyrimidin-2-ones (DHPMs) using mesoporous aluminosilicate (AlKIT-5) catalyst with cage type pore structure, Tetrahedron, 65: 10608-10611.

[14] Murata, H., Ishitani, H., Iwamoto, M. (2010). Synthesis of Biginelli dihydropyrimidinone derivatives with various substituents on aluminium-planted mesoporous silica catalyst. Org. Biomol. Chem., 8: 1202-1211.

[15] Hosseini, M.M., Kolvari, E., Koukabi, N., Ziyaei, M., Zolfigol, M.A. (2016). Zirconia Sulfuric Acid: An Efficient Heterogeneous Catalyst for the One-Pot Synthesis of 3,4Dihydropyrimidinones Under Solvent-Free Conditions. Catal. lett, 146(6): 1040-1049.

[16] Dubey, A., Mishra, B.G., Sachdev, D., Sowmiya, M. (2008). Heterogeneous liquid phase synthesis of 3,4-Dihydropyrimidine-2(1H)ones using aluminated mesoporous silica. React. Kinet. Catal. Lett., 93(1): 149-155. 
[17] Satyanarayana, K.V.V., Atchuta Ramaiah, P., Murty, Y.L.N., Ravi Chandra, M., Pammi, S.V.N. (2012). Recyclable $\mathrm{ZnO}$ nano particles: Economical and green catalyst for the synthesis of a coupling of propargylamines under solvent free conditions. Catalysis Communications, 25: 50-53.

[18] Bhuyan, D., Saikia, M., Saikia, L. (2018). $\mathrm{ZnO}$ nanoparticles embedded in SBA-15 as an efficient heterogeneous catalyst for the synthesis of dihydropyrimidinones via Biginelli condensation reaction. Microporous and Mesoporous Materials, 256: 39-48.

[19] Laxminarayan, R., Matoso, P., Pant, S., Brower, C., Rottingen, J-A., Klugman, K., Davies, S. (2016). Access to effective antimicrobials: a worldwide challenge. Lancet, 387(10014): 168175.

[20] Lu, Q., Wang, Z., Li, J., Wang, P., Ye, X. (2009). Structure and Photoluminescent Properties of $\mathrm{ZnO}$ Encapsulated in Mesoporous Silica SBA-15 Fabricated by Two-Solvent Strategy. Nanoscale Res. Lett., 4: 646-654.

[21] Jiang, Q., Wu, Z.Y., Wang, Y.M., Cao, Y., Zhou, C.F., Zhu, J.H. (2006). Fabrication of photoluminescent $\mathrm{ZnO} / \mathrm{SBA}-15$ through directly dispersing zinc nitrate into the asprepared mesoporous silica occluded with template. J. Mater. Chem., 16: 1536-1542.

[22] Betiha, M.A., Hassan, M.A.H., Al-Sabagh, M. A., Khder, A.El.R.S., Ahmed, E.A. ( 2012). Direct synthesis and the morphological control of highly ordered mesoporous AlSBA-15 using urea-tetrachloroaluminate as a novel aluminum source. J. Mater. Chem., 22: 1755117559.

[23] Saikia, M., Bhuyan, D., Saikia, L. (2015). Keggin type phosphotungstic acid encapsulated Chromium (III) Terephthalate Metal Organic Framework as active catalyst for Biginelli condensation. Applied Catalysis A: General, 505 : 501-506

[24] Holder, I.A., Boyce, S.T. (1994). Agar well diffusion assay testing of bacterial susceptibility to various antimicrobials in concentrations non-toxic for human cells in culture. Burns, 20: 426-429.

[25] Kundu, S.K., Mondal, J., Bhaumik, A. (2013). Tungstic acid functionalized mesoporous SBA-15: A novel heterogeneous catalyst for facile one-pot synthesis of 2 -amino- $4 \mathrm{H}$ chromenes in aqueous medium. Dalton Trans., 42: 10515-10524.

[26] Girija, D., Naik, B.H.S., Kumar, V.B., Sudhamani, C.N., Harish, K.N. (2014). Fe3O4 nanoparticles supported $\mathrm{Ni}$ (II) Complexes: a magnetically recoverable catalyst for Biginelli reaction. Arab. J. Chem., 12(3): 420-428.
[27] Kolvari, E., Koukabi, N., Armandpour, O. (2014). A simple and efficient synthesis of 3, 4-dihydropyrimidin-2-(1H)-ones via Biginelli reaction catalyzed by nanomagneticsupported sulfonic acid. Tetrahedron, 70: 1383-1386.

[28] Ghasemi, Z., Orafa, F.F., Pirouzmand, M., Zarrini, G., Kojanag, B.N., Salehi, R. (2015). $\mathrm{Zn}^{2+}$ / MCM-41 catalyzed Biginelli reaction of heteroaryl aldehydes and evaluation of the antimicrobial activity and cytotoxicity of the pyrimidone products. Tetrahedron Letters, 56 (46): 6393-6396.

[29] Khatri, C.K., Rekunge, D.S., Chaturbhuj, G.U. (2016). Sulfated polyborate: a new and eco-friendly catalyst for one-pot multicomponent synthesis of 3,4-dihydropyrimidin$2(1 \mathrm{H})$-ones/thiones via Biginelli reaction. New J. Chem., 40: 10412-10417.

[30] Pramanik, M., Bhaumik, A. (2014). Phosphonic Acid Functionalized Ordered Mesoporous Material: A New and Ecofriendly Catalyst for One-Pot Multicomponent Biginelli Reaction under Solvent-Free Conditions. Appl. Mater. Interfaces, 6: 933-941.

[31] Moitra, D., Ghosh, B.K., Chandel, M., Ghosh, N.N. (2016). Synthesis of BiFeO3 nanowireReduced Graphene Oxide based Magnetically Separable nanocatalyst and it's Versatile Catalytic Activity towards Multiple Organic Reactions. RSC Adv., 6: 97941-97952.

[32] Savanur, H.M., Kalkhambkar, R.G., Aridoss, G., Laali, K.K., (2016). [bmim(SO3H)][OTf]/ [bmim] [X] and Zn(NTf2)2/[bmim][X] (X = PF6 and BF4) Efficient Catalytic Systems for the Synthesis of Tetrahydropyrimidin-ones (thiones) via the Biginelli Reaction. Tetrahedron Letters, 57: 3029-3035.

[33] Barbero, M., Cadamuro, S., Dughera, S. (2017). A Brønsted acid catalysed enantioselective Biginelli reaction. Green Chem., 19: 1529-1535.

[34] Ali, B., Esmail, D., Rostamnia, S. (2018). Catalytic behaviour of perchloric acid on silica mesoporous SBA-15 as a green heterogeneous Bronsted acid in heterocyclic multicomponent reactions. International Nano Letters, 8: 4147.

[35] Pasupathi, M., Santhi, N., Pachamuthu, M.P., Mangai, G.A., Ragupathi, C. (2018). Aluminium and titanium modified mesoporous TUD-1: A bimetal acidcatalyst for Biginelli reaction. J. Mol. Struct., 1160: 161-166.

[36] Verma, A., De, D., Tomar, K., Bharadwaj, P.K. (2017). An Amine Functionalized MetalOrganic Framework as an Effective Catalyst for Conversion of $\mathrm{CO}_{2}$ and Biginelli Reactions. Inorg. Chem., 56(16): 9765-9771. 
[37] Yao, N., Lu, M., Liu, X.B., Tan, J., Hu, Y.L. (2018). Copper-doped mesoporous silica supported dual acidic ionic liquid as an efficient and cooperative reusability catalyst for Biginelli reaction. J. Mol. Liq., 262: 328-335.

[38] Arena, F., Barbera, K., Italiano, G., Bonura, G., Spadaro, L., Frusteri, F. (2007). Synthesis, characterization and activity pattern of $\mathrm{Cu}-$ $\mathrm{ZnO} / \mathrm{ZrO} 2$ catalysts in the hydrogenation of carbon dioxide to methanol. Journal of Catalysis, 249: 185-194.
[39] Yanhua, W., Jingchang, Z., Hengyong, X. (2006). Interaction between $\mathrm{Pd}$ and $\mathrm{ZnO}$ during Reduction of $\mathrm{Pd} / \mathrm{ZnO}$ Catalyst for Steam Reforming of Methanol to Hydrogen. Chinese Journal of Catalysis, 27(3): 217-222.

[40] Liu, L., Oza, S., Hogan, D., Perin, J., Rudan, I., Lawn, J.E., Cousens, S., Mathers, C., Black R.E. (2015). Global, regional, and national causes of child mortality in 2000-13, with projections to inform post-2015 priorities: an updated systematic analysis. Lancet, 385 (9966): 430-440. 